\title{
EFFECT OF COMBINED SORBENT PREPARATION ON GROWTH, PERFORMANCE AND HAEMATOBIOCHEMICAL ALTERATIONS IN BROILER CHICKENS UNDER THE INFLUENCE OF T-2 TOXIN AND DEOXYNIVALENOL MIXED TOXICOSIS
}

\author{
G. O. Khmelnitskiy and V. D. Korzunenko* \\ Department of Veterinary Medicine, National University of Life and Environmental Sciences of Ukraine, Kyiv, \\ Ukraine
}

\begin{abstract}
The combined sorbent preparation consists of anthracite, saponite and inactivated yeasts. To determine the detoxification activity of the combined sorbent preparation on the mixed chickens' mycotoxicosis, thirty, two-weeks-old chickens cross "Ross 308" were divided into three groups: A (control); B (T-2 toxin and deoxynivalenol); C (T-2 toxin, deoxynivalenol and the combined sorbent preparation). Chickens were weighed every week, hematological and serum biochemical investigations were provided at 28-th and 42-nd day of chicken's age. Applying of the combined sorbent preparation in T-2 toxin and deoxynivalenol mixed chickens toxicosis at $3 \%$ by weight of the feed, neutralizes the negative effects of mycotoxins on the bird. It manifests high yield carcass weight and lowers the feed conversion, with almost no variations in hematological and serum biochemical parameters of blood.
\end{abstract}

Key words: Broiler chickens combined sorbent preparation, T-2 toxin, deoxynivalenol, haematobiochemical parameters

\section{INTRODUCTION}

There are more than 40 trichothecen mycotoxins (fusariotoxins), secondary metabolites of various representatives of microscopic fungi Fusarium known T-2 toxin and deoxynivalenol (vomitoxin, DON) are the most common trichothecenes in Ukraine, the content of which often exceeds the maximum permissible levels in the animal feedstuff. Feedstuff, contaminated by trichothecenes, causes poor feed efficiency, reduced growth and impaired immune status of broiler, increasing their death.

A characteristic feature of T-2 toxin is dermonecrotic action while DON causes vomiting. Both of toxins have embryotoxic, teratogenic, mutagenic, carcinogenic action (Tutelyan and Kravchenko, 1985).

Specific treatment of mycotoxicosis is not developed. The treatment includes such arrangements as exclusion suspect feed from the diet, absolute diet and gastric lavage with $3 \%$ solution of sodium bicarbonate, bulk cathartics (Achmetov et al., 2001; Malinin et al., 2002). Feed additives and premixes, which include enterosorbents, are commonly used to prevent mycotoxicosis too (Beaver et al., 1989; Lohov et al., 2008). There is a wide range of proposed sorbents on the market of veterinary drugs: inorganic, organic, and combined (Gorcovenko et al., 2006; Berezovskiy, 2009; Kotsyumbas et al., 2009). Most sorbents are ineffective against fusariotoxins (Ivanov et al., 2008; Grigorenko, 2011), so the development of new combined sorbent is promising and relevant.

\section{MATERIALS AND METHODS}

Site and animals

This study was conducted in the Pharmacology and Toxicology Laboratory and vivarium of Department of Veterinary medicine, Nation University of Life and Environmental Sciences of Ukraine, Kyiv, Ukraine. This experiment had been approved by the institution's Ethics Committee. Thirty two-weeks-old chickens cross "Ross 308" were used. They were kept in bird-cages at room temperature with ventilation and under natural light and dark periods, and they received water and animal feed ad libitum. Mycotoxins-free feed was procured from local feed manufacturer.

\section{Experimental design}

Cultures of Fusarium sporotrichiella v. poae strain 407/4 and Fusarium macroceras strain 108270 were used for the production of T-2 toxin and DON respectively.

The combined sorbent preparation was developed on the basis of sorbtion capacity of different minerals. Carbon sorbents (anthracite, birch activated carbon), lignin and saponite show the highest sorption capacity of T2 toxin and deoxynivalenol. The combined sorbent preparation consists of anthracite $70 \%$, saponite $20 \%$ and inactivated yeasts $10 \%$. All components have meshed not more than $0.2 \mathrm{~mm}$.

*Corresponding e-mail address: korzunenko82@mail.ru 


\section{G. O. Khmelnitskiy and V. D. Korzunenko}

Two-weeks-old chickens cross "Ross 308 " were divided randomly into three groups of 10 birds each. Dietary levels of T-2 toxin and DON in experimental diets were adjusted by adding calculated amount of mouldy wheat to the diet. The experimental diets containing graded concentration of T-2 toxin and DON were fed at $3.2 \mathrm{ppm}$ and 0.14 ppm respectively in group $\mathrm{B}$ and $\mathrm{C}$ from 15 -th to 42 -nd day of age. Group $\mathrm{C}$ additionally received the combined sorbent preparation at $3.0 \%$ dietary level. Group A birds did not receive T-2 toxin, DON and sorbent and served as control.

To study the effect of T-2 toxin on growth, experimental chickens were weighed individually every week and weekly feed intake was also recorded to calculate feed conversion ratio (FCR) of each treatment group.

\section{Haematological and serum biochemical analysis}

Blood samples were collected from jugular vein using heparin solution anticoagulant from five birds of each group at 28-th and 42 -nd day of age. Serum was separated and stored at $4^{\circ} \mathrm{C}$. Individual whole blood samples were analyzed for haemoglobin $(\mathrm{Hb})$ value, red cell count, white cell count, erythrocyte sedimentation rate using common methods. Individual serum samples were analyzed for serum total protein, calcium and phosphorus, creatinine, uric acid, total bilirubin values, aspartate transaminase (AST), alanine transaminase (ALT), alkaline phosphatase (ALP) activity, thymol test using common methods.

\section{RESULTS AND DISCUSSION Body weight investigations}

Significant reduction in body weight was observed in group B starting from 4-th week; group C from 5-th week compared to group A (Table 1). The highest FCR was recorded in group B whereas lowest FCR was recorded in group C. The reduction in body weight of chickens in the present study due to T-2 and DON induced toxicosis was treatment dependent that is similar as described by Pande (2006). It may due to inflammation, contact erosion and irritation of alimentary tract resulting into decrease in feed consumption and consequently decrease in body weight of toxicated birds. However, small difference in body weights of chickens group $\mathrm{C}$ in comparison to group A confirms positive effect of sorbent preparation.

\section{Haematological analysis}

At 28-th and 42-nd days of age $\mathrm{Hb}$ values of chickens group B were significantly $(\mathrm{P}<0.05)$ lower compared to control (Table 2). The reduction in $\mathrm{Hb}$ in the present study recorded may be due to decreased protein synthesis in toxicated chickens. The results of red cell count of experimental chickens at both the period of observations indicated non-significant effect of graded levels of dietary T-2 toxin and DON.

There was leucopenia elucidated in the blood of chickens group B and C, upon that white cell count in the blood of chickens group B was to $28 \%$ less at 28 -th day of age and to $27 \%$ less at 42 -nd day compared to control group. White cell count in the blood of chickens group C was $8 \%$ less at 28 -th day of age, but was not significantly different from control at 42 -nd day. The significant effect of dietary mycotoxins at eosinophil count was observed in the blood of chickens group B and C during present experiment. Eosinophilia may be due to the reactions of hypersensitivity of the body. There was significant $(p<0.01)$ rise in erythrocyte sedimentation rate of chickens group B (approx. 1.7 times) compared to control. However, the difference in erythrocyte sedimentation rate among experimental groups $\mathrm{A}$ and $\mathrm{C}$ was not significant.

\section{Serum biochemical analysis}

Total serum protein in chickens was significantly influenced by the experimental treatments. The total protein value in group B was significantly ( $\mathrm{p}<0.001)$ lowered at both the period of observations (approx. 1.5 times) in contrast to group A (Table 3). On comparison of serum calcium and phosphorus values of the experimental groups, it was observed that phosphorus value was significantly $(\mathrm{p}<0.05)$ reduced in group B as compared to other groups (A and C) during experiment. However, the difference in serum calcium values among all experimental was not significant. At 28-th and 42-nd days of age serum creatinine values of chickens group B increased approx. 1.5 times and 1.3 times compared to control respectively.

The rise in serum creatinine values may be due to the renal insufficiency. There was significant reduction in serum uric acid of chickens group B at 28-th day $(\mathrm{p}<0.01)$ and 42-nd day $(\mathrm{p}<0.001)$ of age compared to control group. There was significant $(\mathrm{p}<0.001)$ rise in serum total bilirubin values of chickens group B compared to group A during all experiment. Upon that serum total bilirubin values of all experimental groups raised in 2.5 times from 28-th day to 42-nd day of age. 
Effect of combined sorbent preparation in broiler chickens

Table 1 . Mean weekly body weights $(\mathrm{g})$ of experimental chickens from various treatment groups, $\mathrm{M} \pm \mathrm{SD}, \mathrm{n}=5$

\begin{tabular}{|llll|}
\hline Age (weeks) & \multicolumn{3}{c|}{ Treatment } \\
\hline 2-nd & A & B & C \\
3-rd & $419.1 \pm 8.2$ & $434.2 \pm 8.7$ & $424.3 \pm 15.5$ \\
4-th & $849.7 \pm 15.2$ & $798.4 \pm 18.1$ & $848.7 \pm 8.9$ \\
5-th & $1272.0 \pm 28.3$ & $1043.1 \pm 19.8^{\mathrm{c}}$ & $1195.7 \pm 25.5$ \\
6-th & $1984.8 \pm 100.6$ & $1410.2 \pm 48.9^{\mathrm{c}}$ & $1854.6 \pm 71.7$ \\
FCR & $2574.8 \pm 148.4$ & $1698.2 \pm 60.3^{\mathrm{c}}$ & $2375.8 \pm 76.0$ \\
\hline
\end{tabular}

A - control group; B - T-2 toxin and DON 3.2 ppm and 0.14 ppm dietary level respectively; C - T-2 toxin, DON and combined sorbent preparation $3.2 \mathrm{ppm}, 0.14 \mathrm{ppm}$ and $3.0 \%$ dietary level respectively. FCR - feed conversion ratio. ${ }^{\mathrm{c}}$ Significant difference between $\mathrm{A}$ and $\mathrm{B}(\mathrm{p}<0.01)$.

Table 2. Haematological parameters of broiler chickens after 4 weeks of the experiment, $\mathrm{M} \pm \mathrm{SD}, \mathrm{n}=5$

\begin{tabular}{|llll|}
\hline Parameter & \multicolumn{3}{c|}{ Treatment } \\
\hline Haemoglobin, g/L & $\mathrm{A}$ & $\mathrm{B}$ & $\mathrm{C}$ \\
Red cell, trillion cells/L & $87.00 \pm 1.05$ & $82.80 \pm 1.46^{\mathrm{b}}$ & $85.80 \pm 1.59$ \\
White cell, billion cells/L & $2.70 \pm 0.10$ & $2.94 \pm 0.05$ & $2.76 \pm 0.05$ \\
Erythrocyte sedimentation rate, $\mathrm{mm} / \mathrm{hr}$ & $15.24 \pm 0.45$ & $11.08 \pm 0.85^{\mathrm{c}}$ & $14.52 \pm 0.91$ \\
\hline
\end{tabular}

A - control group; B - T-2 toxin and DON $3.2 \mathrm{ppm}$ and $0.14 \mathrm{ppm}$ dietary level respectively; C - T-2 toxin, DON and combined sorbent preparation $3.2 \mathrm{ppm}, 0.14 \mathrm{ppm}$ and $3.0 \%$ dietary level respectively.

${ }^{\mathrm{b}}$ Significant difference between A and B $(\mathrm{p}<0.05)$, ${ }^{\mathrm{c}}$ Significant difference between A and B $(\mathrm{p}<0.01)$.

On comparison of ALT activity of the experimental groups, it has been observed that ALT activity was significantly reduced in group B compared to other groups (A and C) at 28-th day $(\mathrm{p}<0.001)$ and 42-nd day ( $\mathrm{p}<$ 0.05) of age. The results of AST activity of experimental chickens at both the period of observations indicated non-significant effect of graded levels of dietary mycotoxins. There was significant $(\mathrm{p}<0.01)$ rise in ALP activity of chickens group B compared to control group during all experiment. At 28-th day of age there was significant $(\mathrm{p}<0.05)$ rise in ALP activity of chickens group $\mathrm{C}$ but at 42 -nd day of age there was no difference compared to control group. There was positive thymol test in group B at both the period of observations in contrast to group A and C. Reduction in ALT activity, rise in ALP activity and positive thymol test may be due to hepatotoxic effect of T-2 toxin and DON. On the contrary, increase in ALT has been reported in broiler chicks fed 4 ppm T-2 toxin from 7 to 55 days (Raina et al., 1991). However, a decrease in ALT level was reported in broiler chickens after 35 days of feeding with $0.3 \mathrm{ppm}$ AF and 3 ppm T2 toxin (Raju et al., 2000).

Hence, it may be concluded that T-2 toxin at $3.2 \mathrm{ppm}$ and DON at $0.14 \mathrm{ppm}$ level could adversely affect the health of broiler chickens when fed from 28-th day of age to 42-nd day of age. The study also indicated the potential of T-2 toxin to interact significantly with DON in altering haematological and serum biochemical constituents like $\mathrm{Hb}$ value, white cell count, erythrocyte sedimentation rate, total protein, phosphorus, creatinine, uric acid, total bilirubin values, ALT and ALP activity. Application of the combined sorbent preparation in experimental mixed T-2 and DON toxicosis of chickens at $3 \%$ by weight of the feed neutralizes the negative effects of mycotoxins on the adsorbents to animal feed provides versatile tools of preventing bird. It manifests high yield carcass weight and lower rates of feed conversion, with almost no variations in hematological and serum biochemical parameters of blood. This research confirms that the addition of different adsorbents or of very promising derivatized mycotoxicosis (Huwig et al., 2001). 
G. O. Khmelnitskiy and V. D. Korzunenko

Table 3. Serum biochemical parameters of broiler chickens after 4 weeks of the experiment, $M \pm S D, n=5$

\begin{tabular}{|llll|}
\hline Parameter & \multicolumn{2}{c|}{ Treatment } \\
\hline Total protein, g/L & $36.80 \pm 0.73$ & $\mathrm{~B}$ & $\mathrm{C}$ \\
Total bilirubin, $\mu \mathrm{mol} / \mathrm{L}$ & $10.40 \pm 0.68$ & $23.20 \pm 1.07^{\mathrm{d}}$ & $35.80 \pm 0.97$ \\
Thymol test, units & $0.25 \pm 0$ & $15.04 \pm 0.57^{\mathrm{d}}$ & $8.90 \pm 0.81$ \\
Uric acid, mmol/L & $2.14 \pm 0.07$ & $0.40 \pm 0.04^{\mathrm{c}}$ & $0.25 \pm 0$ \\
Creatinine, mmol/L & $0.03 \pm 0.01$ & $1.64 \pm 0.02^{\mathrm{d}}$ & $2.06 \pm 0.07$ \\
Calcium, mmol/L & $2.45 \pm 0.07$ & $0.04 \pm 0.01^{\mathrm{d}}$ & $0.03 \pm 0.01$ \\
Phosphorus, mmol/L & $2.36 \pm 0.12$ & $2.61 \pm 0.02$ & $2.66 \pm 0.06$ \\
ALT, U/L & $3.10 \pm 0.20$ & $2.04 \pm 0.04^{\mathrm{b}}$ & $2.35 \pm 0.08$ \\
AST, U/L & $27.33 \pm 0.65$ & $2.37 \pm 0.12^{\mathrm{b}}$ & $3.00 \pm 0.12$ \\
ALP, U/L & $320.69 \pm 12.6$ & $27.80 \pm 0.88$ & $27.93 \pm 0.48$ \\
\hline
\end{tabular}

A - control group; B - T-2 toxin and DON 3.2 ppm and 0.14 ppm dietary level respectively; C - T-2 toxin, DON and combined sorbent preparation $3.2 \mathrm{ppm}, 0.14 \mathrm{ppm}$ and $3.0 \%$ dietary level respectively.

${ }^{\mathrm{b}}$ Significant difference between A and B $(\mathrm{p}<0.05)$, ${ }^{\mathrm{C}}$ Significant difference between A and B $(\mathrm{p}<0.01)$.

${ }^{\mathrm{d}}$ Significant difference between A and B $(\mathrm{p}<0.001)$.

\section{ACKNOWLEDGEMENT}

The authors thank Nation University of Life and Environmental Sciences of Ukraine for the facilities provided.

\section{REFERENCES}

1. Achmetov FG, Ivanov AV and Tremasov MY (2001). Mycotoxicosis prevention of animals. Veterinary 2: 47-50.

2. Beaver RM, Wilson DM and James MA (1989). Distribution of aflotoxin in tissues of growing pigs fed an aflatoxin contaminated diet with a high affinity alumosilicate sorbent. Veterinary and Human Toxicology 32 (1): $16-18$.

3. Beresovkiy AV (2009). Bird's mycotoxicosis, strategy and tactics of prevention. Materials of the X Conference on Ukrainian poultry industry with international participation, Kharkov, pp. 19-27.

4. Gorcovenko N, Makarov Yu and Serebryakova V (2006). Zeolites usage for broiler detoxication. Poultry 5: 18-19.

5. Grigorenko ME (2011). Sorbents and perspectives of their use in animal mycotoxicosis. Veterinary Biotechnology 18: 47-54.

6. Huwig A, Freimund S, Kappel O and Dutler H (2001). Mycotoxin detoxication of animal feed by different adsorbents. Toxicology Letters 122 (2): 179-188.

7. Ivanov AV, Tremasov MY and Nutrudinov MG (2008). Actual problems of mycotoxicosis prevention. Veterinarian 2: 2-3.

8. Kotsumbas IY, Brezvin OM and Kushnir RO (2009). Sorbents usage in the practice of veterinary medicine. Scientific and Technical Report of Institute of Biology and State Scientific-Research Control Institute of Veterinary Medicinal Products and Feed Additives 10 (4): 584-587.

9. Lohov VV, Zasekin MD and Kolesnikov OO (2008). Application of effective detoxifying tools in the Ukrainian poultry. Veterinary medicine of Ukraine 9: 40-43.

10. Malinin OA, Khmelnitskiy GO and Khutsan AT (2002). Veterinary toxicology. Khorsun-Shevchenkovskiy pp. 464. 
11. Pande VV, Kurkure NV and Bhandarkar AG (2006). Effect of T-2 toxin on growth, performance and haematobiochemical alterations in broilers. Indian Journal of Experimental Biology 44: 86-88.

12. Raina JS, Roy KS and Singh B (1991). Biochemical and histochemical studies in experimental mycotoxicosis in chicks. Indian Journal of Animal Sciences 62: 1276-1281.

13. Raju MVLN and Devegowda G (2000). Influence of esterified-glucomannan on performance and organ morphology, serum biochemistry and haematology in broilers exposed to individual and combined mycotoxicosis (aflatoxin, ochratoxin and T2 toxin). British Poultry Science 41: 640-650.

14. Tutelyan VA and Kravchenko LV (1985). Mycotoxins (Medical and biological aspects). Medicine, Moscow. pp. 320. 